\title{
An Oriented Attachment Kinetics for Ligand Capped Nanocrystal: Coarsening of Thiol-PbS Nanoparticles
}

Jing Zhang a , Yonghao Wang ${ }^{\mathrm{a}}$, Jinsheng Zheng ${ }^{\mathrm{a}}$, Feng Huang ${ }^{\mathrm{a}}$, Dagui Chen ${ }^{\mathrm{a}}$, Youzhao

$$
\text { Lan }^{\mathrm{a}} \text {, Guoqiang Ren }{ }^{\mathrm{a}} \text {, Zhang Lin }{ }^{\mathrm{a}, *} \text { Chen Wang }{ }^{\mathrm{b}}
$$

${ }^{a}$ State Key Lab of Structural Chemistry, Fujian Institute of Research on the Structure of Matter, Chinese Academy of Sciences, Fuzhou, Fujian, 350002, People's Republic of China

${ }^{\mathrm{b}}$ National Center for NanoScience and Technology, Beijing 100080, People's Republic of China

\section{Supporting Information:}

1. The quantitative analysis of IR spectrum to detect the amount of thiol on the surface of particles.

The quantitative analysis of IR spectrum was conducted to detect the amount of surface adsorbed thiol. In detail, $\operatorname{KSCN}\left(2100 \mathrm{~cm}^{-1}\right)$ was taken as the internal standard and mixed with $\mathrm{KBr}$. Different $\mathrm{PbS}$ samples with certain quantitative amount were blended with above powder respectively, followed with pelleting and measuring. Figure S1 shows the truncated IR spectra of dodecanethiol capped $\mathrm{PbS}$ and KSCN mixture. In the spectra, the absorption bands of $-\mathrm{SH}\left(2550 \mathrm{~cm}^{-1}\right)$ in dodecanethiol $\left(\mathrm{C}_{12} \mathrm{H}_{25} \mathrm{SH}\right)$ was not detected, for their bonding to the $\mathrm{PbS}$ particles. So the absorption bands of $-\mathrm{CH}_{2}-\left(2920 \mathrm{~cm}^{-1} \square 2850 \mathrm{~cm}^{-1}\right)$ was used for the quantitative analysis.

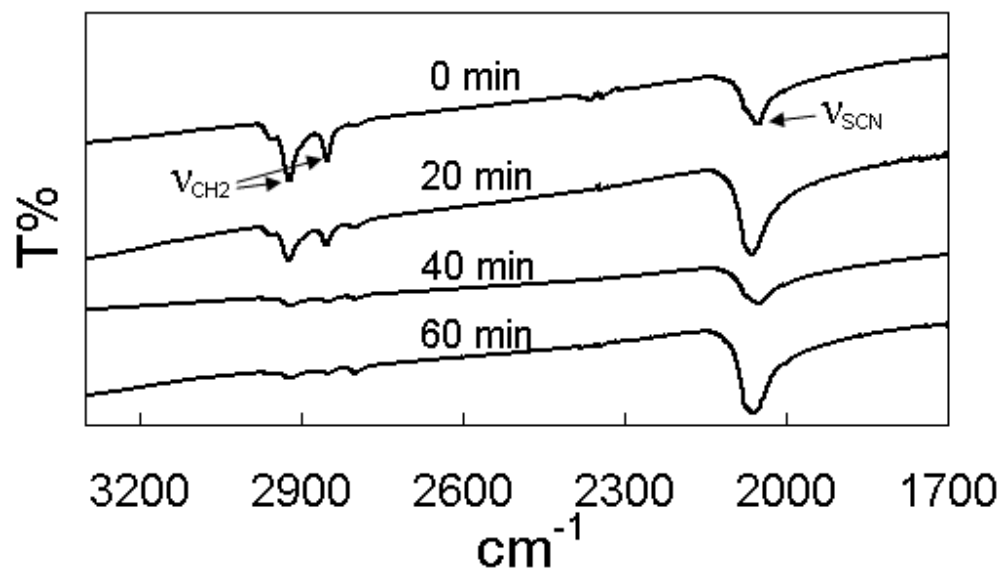


Figure S1. IR spectra of the mixture of dodecanethiol capped $\mathrm{PbS}$ and Potassium. Thiocyanate was used as the internal standard for quantitative analysis. The $\mathrm{PbS}$ particles was hydrothermally treated at $100^{\circ} \mathrm{C}$ for $0 \mathrm{~min}, 20 \mathrm{~min}, 40 \mathrm{~min}, 60 \mathrm{~min}$, respectively.

With the baseline method, the relative content of thiol vs coarsening time in the $\mathrm{PbS}$ system was quantitatively analyzed by the Lambert-Beer law. As shown in Table $\mathrm{S} 1$, the amount of dodecanethiol on the $\mathrm{PbS}$ surfaces decreases gradually. When the pure OA-based growth approaches to the end(around $70 \mathrm{~min}$ at $100^{\circ} \mathrm{C}$ ), the surface capping ligands are almost desorbed.

Table S1. The relative content of $\mathrm{C}_{12} \mathrm{H}_{25} \mathrm{SH}$ vs time at $100^{\circ} \mathrm{C}$ in the $\mathrm{PbS}$ system by hydrothermal treatments.

\begin{tabular}{cc}
\hline Time (min) & Content (\%) \\
\hline 0 & 100 \\
20 & 29 \\
40 & 19 \\
60 & 6 \\
\hline
\end{tabular}

\section{The applicability of the OA kinetic model.}

The developed kinetic model was extended to fit the OA growth of mercaptoethanolcapped nanocrystalline $\mathrm{ZnS}$ in aqueous solution performed by Huang et al. ${ }^{31}$ The calculated results are shown in Figure S2, which is agreed with the experimental data. Table $\mathbf{S} 2$ is the corresponding values by fitting.
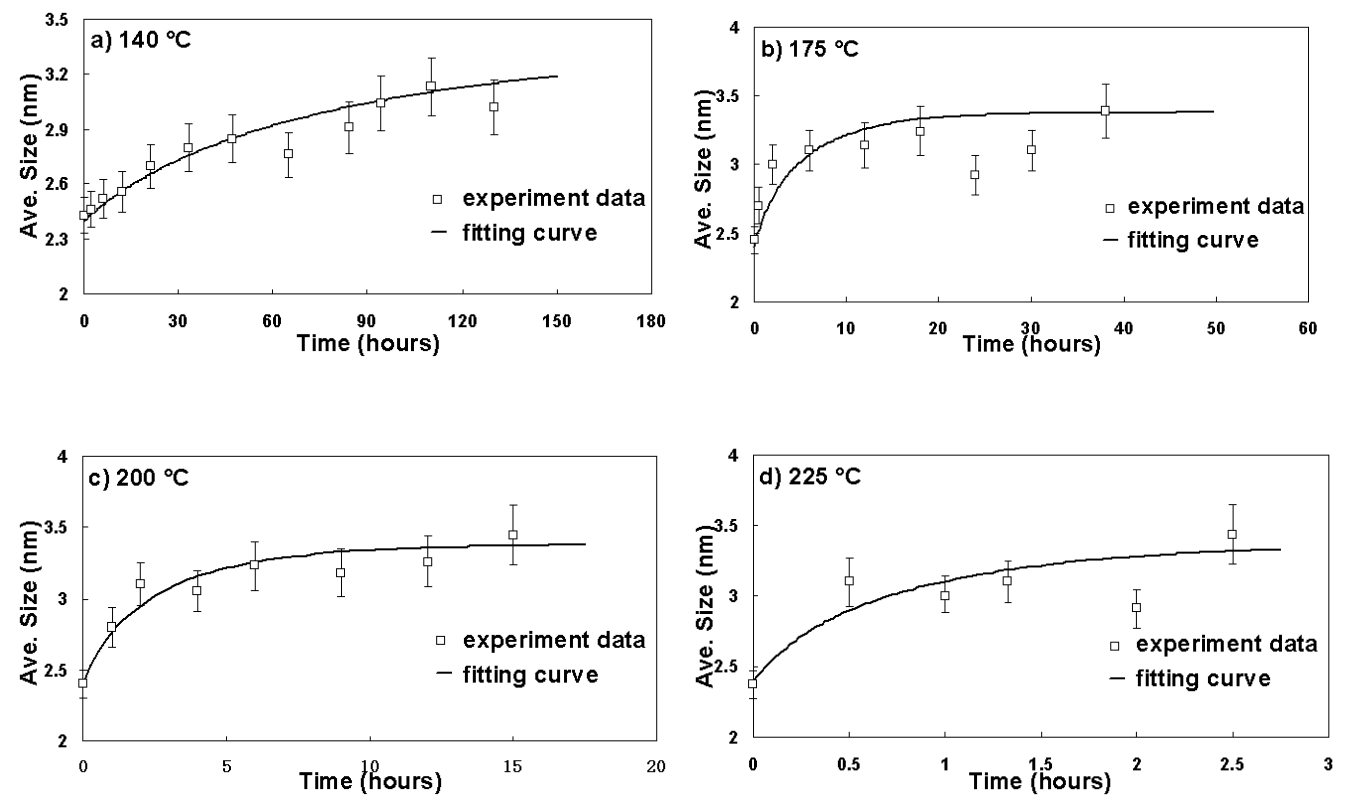
Figure S2. Experimental data and fitting results showing the mean size vs time at each temperature in the system of mercaptoethanol-capped $\mathrm{ZnS}$ nanoparticles by hydrothermal treatments.

Table S2. Estimated Values by Fitting the Experimental Data

\begin{tabular}{ccc}
\hline$T$ & $R_{1}$ & $K_{1}$ \\
$\left({ }^{\circ} \mathrm{C}\right)$ & $(\mathrm{nm})$ & $\left(=D_{1} \cdot N_{1(0)}\right)$ \\
\hline 140 & 1.22 & $1.8 \times 10^{2}$ \\
175 & 1.23 & $2 \times 10^{3}$ \\
200 & 1.20 & $6 \times 10^{3}$ \\
225 & 1.19 & $2 \times 10^{4}$ \\
\hline
\end{tabular}

